\title{
The Assessment of the Quality of Life in Visually Impaired People with Different Level of Physical Activity
}

\author{
Authors' contribution: \\ A) conception and design \\ of the study \\ B) acquisition of data \\ C) analysis and interpretation \\ of data \\ D) manuscript preparation \\ E) obtaining funding
}

\author{
Anna Malwina Kamelska ${ }^{\text {A-D }}$, Krzysztof Mazurek $^{\text {A,C-E }}$ \\ Jozef Pilsudski University of Physical Education in Warsaw, Poland
}

ABSTRACT

Quality of life (QOL) is associated with factors such as health, physical functioning, life satisfaction, a sense of happiness, and others. In case of disabled people, much attention is paid to their QOL rather than only the improvement of physiological variables. In a group of blind and visually impaired people, the effect of physical activity (PA) on the socialization process, the ability to explore own personality traits, developing creativity, and more motivation and desire to overcome the difficulties associated with visual impairment were observed.

The study involved 53 people: visually impaired (NT) sedentary lifestyle people $(\mathrm{n}=18 ; 51 \pm 12$ years $)$ and visually impaired tandem cycling athletes $(\mathrm{N})(\mathrm{n}=17$; $42 \pm 13$ years). Properly sighted people $(\mathrm{P})(\mathrm{n}=18 ; 38 \pm 12$ years $)$ were partners in tandem with visually impaired athletes. To determine the level of PA, the International Physical Activity Questionnaire (IPAQ) was used. The WHO-Quality of Life (WHO-QOL-BREF), the National Eye Institute 25-item Visual Functioning Questionnaire (NEI VFQ-25, version 2000), and the Retina AMD Poland Association questionnaire were used to assess QOL.

In visually impaired athletes, significantly greater PA with moderate intensity, moving by bike, and energy expenditure for vigorous recreational exercise and sport in leisuretime was found. Sedentary lifestyle people mainly participated in moderate physical activity around the house. Significant greater satisfaction with health was observed in the case of visually impaired athletes in comparison with NT. All disabled groups rarely had negative feelings such as despair, depression, and anxiety.

Moderate correlations between variables according to physical activity and quality of life in all participants were observed. The meaningfulness of life and life satisfaction also depended on cycling training and moderate physical activity around the house. The obtained data indicate that all available forms of regular PA in visually impaired people could have a beneficial effect on their quality of life.

KEYWORDS 


\section{Introduction}

Quality of life (QOL) is associated with factors such as health (health-related quality of life HRQOL), physical functioning, life satisfaction, a sense of happiness, and others. Independently of the adopted definition, the optimal QOL is crucial (Daszykowska, 2006). In the case of disabled people, the type and range of disability, family relationship to a disabled person, material status, and the range of usefulness in the nearest milieu should be taken into account (Karwat, Jabłoński, \& Krupa 2000, pp. 182-186).

Regular physical activity (PA) brings many physiological as well as psychological benefits. Physical capacity is improved, and is associated with a decrease in heart rate (HR) (resting and during submaximal exercise), an increase in stroke volume (SV) (resting and during exercise), and maximal cardiac output (CO). After training, the decease or stabilization of blood pressure (BP) are observed. Proper lipid and glucose profiles are formed.

In the case of disabled people, much attention is paid to their quality of life rather than only the improvement of physiological variables. The most important things for visually impaired people are normal functioning at home, with family, in society, and life without physical or mental ailment.

Because of the rules of adjustment and adaptation in disabled sport, there are many recreational and sporting activities that visually impaired people could participate in. These disciplines include goalball, road cycling, track cycling, athletics, judo, equestrianism, 5-a-side football, rowing, sailing, swimming, and others. Many health benefits for visuallyimpaired people regardless of age or gender also bring participation in physical recreation, e.g., rope jumping (Chen, \& Lin, 2011). There are also newly introduced technologies such as interactive games combined with exercises - "exergames" specially adapted for people with reduced eyesight (Morelli, Folmer, Foley et al., 2011).

Psychological effects achieved through regular physical activity relate mainly to improvement in psychological well-being, decision support, planning, reduction of the level of anxiety, and improvement in sleep quality. Physical exercise also reduces the risk of depression (Mikkelsen, Tolstrup, Flachs et al., 2010; Teychenne, Ball, \& Salmon, 2008), decreases its symptoms, and has a positive impact on improving mood (Ströhle, 2009).Moreover, the physical activity of blind and visually impaired people, e.g., tandem cycling or running with a guide, has an impact on positive relationships with people and shapes social integration. Another motivating factor is the presence of a partner.

In the group of people with disabilities, physical activity improves self-esteem and facilitates their professional and social functioning (Gąciarz, Ostrowska, \& Pańków, 2008). Furthermore, the introduction of training in wheelchair group improves their quality of life (Midha, Schmitt, \& Sclater, 1999).

In the blind and visually impaired group, the effects of physical activity on the socialization process(Movahedi, Mojtahedi, \& Farazyani, 2011), the ability to explore own personality traits, developing creativity (Kuru, \& Karahan, 2008), more motivation and desire to overcome the difficulties associated with visual impairment (Özer, 2001)were observed. As the effect of physical training increase in self-esteem, satisfaction and development of health behavior and social skills were shown (Auxter, Pyfe, \& Huettig, 1997). Recreational downhill skiing leads to comprehensive rehabilitation and social integration of these individuals (Blachura, Blacha, \& Stefanowska, 2010).

The quality of life assessment is more and more common in a lot of research. The problem with finding its most appropriate definition brings more new research methods. Increasingly specific questionnaires characteristic for different diseases are used. Specific scales examine characteristic aspects of the disease (e.g., in case of cancer, visual impairment), patient population (e.g., elderly people),and a specific problem (e.g., pain). This gives the ability to detect specific problems associated with different diseases, an individual approach to each patient, and providing adequate medical care.To assess health related quality of life, the Euro Qol questionnaire (EQ-5D) was used (Langelaan, de Boer, van Nispen et al., 2007). In studies by other authors, the Low Vision Quality of Life (LVQOL) questionnaire was shown to be a highly internally consistent and reliable method for measuring quality of life in the visually impaired 
(Wolffsohn, Cochrane, \&Watt,2000). The Visual Functioning Questionnaire (VFQ-25) is one of the most widely used measures of vision-related quality of life (Langelaan, van Nispen, Knol et al., 2007).

The aim of the study was to compare the quality of life in visually impaired and properly sighed people with different level of physical activity. The impact of regular physical activity in form of tandem cycling on the QOL was also assessed.

\section{Material and methods}

\section{Sample and participants selection:}

The study involved 53 people: visually impaired (NT) sedentary lifestyle people ( $n=18 ; 51 \pm 12$ years) and visually impaired tandem cycling athletes $(\mathrm{N})(\mathrm{n}=17 ; 42 \pm 13$ years $)$. Properly sighted people (P) $(\mathrm{n}=18 ; 38 \pm 12$ years) were partners in tandem with visually impaired athletes.

Visually impaired athletes were functionally sighted and were athletes of different cycling tandem teams and the Polish Blind Society from all over Poland. Inclusion criteria were: visual impairment, which precluded independent cycling, and the declaration of participation in training and the initial and control study. All cyclists had trained for at least five years. Exclusion criteria consisted of: the coexistence of other disabilities and diseases with the exception of overweight and obesity. The sedentary lifestyle group consisted of people whose visual acuity was $\mathrm{V}=0.05-0.3$. Inclusion criteria were also: no medical contraindications to participate in the research program, voluntary notification by the participant, and the male sex.

\section{Study organization}

The experiment was conducted with the understanding of each subject. The questionnaires were performed for the $\mathrm{N}$ group during the pre-season period and for NT from September to October 2013. All respondents gave written informed consent to participate in this study, which was approved by the Senate Research Ethical Committee (number SKE 001-27/2012). The study protocol conforms to the ethical guidelines of the 1975 Declaration of Helsinki as reflected in a priori approval by the institution's human research committee and was followed by the APA Ethics Standard.

\section{Research methods}

\section{Assessment of physical activity (PA)}

To determine the level of physical activity, the International Physical Activity Questionnaire (IPAQ) was used (Booth, 2000; Craig et al., 2003). The questionnaire was validated in a group of healthy subjects by Hagströmer, Oja, and Sjöström (Hagströmer, Oja, \& Sjöström, 2006). It included questions about the physical activity performed during the previous week at work, at home and its surroundings, while moving from place to place, and during leisure time in the form of recreation, exercise, and sport. The results were calculatedas the number of days spent on a specific physical activity per week. The specified time spent on an exercise was calculatedand converted into MET (minutes per week).

\section{Self-assessment of quality of life $(Q O L)$}

WHO-Quality of Life (WHO-QOL-BREF)validated by de Vries and Van Heck (De Vries, \& Van Heck, 1997)and specified questionnaires specially designed for the blind and visually impaired were used. The National Eye Institute 25-item Visual Functioning Questionnaire (NEI VFQ-25, version 2000) wasdesigned in Rand Corporation (http://www.nei.nih.gov/resources/visionfunction/vfq_ia.pdf) and consisted of 26 questions relating to problems faced by people with eyesight impairments in everyday life. The Retina AMD Poland Association questionnaire consisting of 16 questions was also used (http://www.retinaamd.org.pl/). 
The results of the questionnaires were obtained fromthe individual or by telephone interviews. Thus, it was possible to reduce the cost of research and reach inaccessible visually impaired target groups that wished to participate in the study. Properly sighted people $(n=18)$ answered only WHO-QOL-BREF and the IPAQ questionnaires.

\section{Statistical analyses}

The STATISTICA 10.0 program for statistical analyses was used. The mean values were calculated. Comparison between groups was done using the U-Mann-Whitney test and the Kruskal-Wallis test. In the case of statistical significance, the post-hoc Tukey test was used. The correlation between the MET equivalent from the IPAQ questionnaire and quality of life results from questionnaires was shown as a Spearman correlation coefficient.

\section{Results}

\section{Characteristics of the studied population}

In NT, $50 \%$ of respondents had a high school education. In the properly sighted and N, $35 \%$ of respondents hadhigher education.

Visual impairment had occurred since birth in the case of $31 \%$ of untrained visually impaired and $57 \%$ of visually impaired athletes.

In the P, N, and NT groups, $78 \%, 94 \%$, and $69 \%$ of people worked, respectively. People who declared a lack of job from the $\mathrm{N}$ and NT groupssaid it was due to the absence of opportunities to workfor health reasons.

\section{Physical activity of the studied population}

In Table 1, the results of PA in the compared groups and total energy expenditure for physical activity as well as the time spent sitting per week are shown.

Table 1. Nationwide data on the supply and requirements of gymnasiums between 2007/2008 and 2013/2014

\begin{tabular}{|c|c|c|c|c|}
\hline \multirow{2}{*}{ Type of PA } & \multicolumn{3}{|c|}{ Group } & \multirow{2}{*}{$\mathbf{P}$} \\
\hline & $\mathbf{P}$ & $\mathbf{N}$ & NT & \\
\hline Job-related & 1184.4 & 1692.0 & 1303.3 & 0.72 \\
\hline Moderate PA & 432.4 & 728.0 & 153.3 & 0.05 \\
\hline Transportation & 1975.3 & 1003.3 & 1297.2 & 0.26 \\
\hline Moving by bicycle & $535.9^{\mathrm{B}}$ & $237.3^{\mathrm{C}}$ & $3.3^{\mathrm{B}, \mathrm{C}}$ & 0.00 \\
\hline Housework & $355.0^{\mathrm{B}}$ & 431.3 & $755.8^{\mathrm{B}}$ & 0.01 \\
\hline Vigorous PA in the garden or yard & $112.9^{\mathrm{B}}$ & $29.3^{\mathrm{C}}$ & $380.0^{\mathrm{B}, \mathrm{C}}$ & 0.02 \\
\hline Recreation, sport, leisure time & 1094.1 & 708.0 & 573.3 & 0.40 \\
\hline Vigorous PA & $451.8^{\mathrm{B}}$ & 344.0 & $80.0^{\mathrm{B}}$ & 0.00 \\
\hline TEE & 4608.8 & 3834.7 & 3929.7 & 0.87 \\
\hline Time spent sitting & 3948.0 & $2674.0^{\mathrm{C}}$ & $4048.3^{C}$ & 0.10 \\
\hline
\end{tabular}

PA - physical activity; P - properly sighted; N - visually impaired athletes; NT - sedentary visually impaired; TEE - total energy expenditures for physical activity.

p - probability, statistical significance $\mathrm{N}$ and NT were indicated by $\mathrm{C}$ and between $\mathrm{P}$ and NT by B.

Source: own study.

Significant differences between all groups were shown as a p value (post-hoc results were described below). The highest MET value of housework was observed inNT, although vigorous PA for recreation and sport in leisure time was greater in the $\mathrm{P}$ and $\mathrm{N}$ groups, respectively.

MET equivalent in the NT group was different from $\mathrm{P}$ in the case of cycling $(\mathrm{p}=0.00)$, vigorous PA in the garden or yard $(\mathrm{p}=0.05)$, and vigorous $\mathrm{PA}$ in leisuretime $(\mathrm{p}=0.01)$. Physical activity inNT was different from $\mathrm{N}$ according to vigorous $\mathrm{PA}$ in the garden or yard $(\mathrm{p}=0.01)$ and sitting on a weekend days $(\mathrm{p}=0.02)$. 
There were no statistically significant correlations between the age of subjects and MET equivalent $(\mathrm{r}<0.40)$.

\section{Quality of life in the studied population}

The results regarding quality of life obtained from the WHO-QOL-BREF are shown in Table 2. Significant differences between groups were observed in the case of the satisfaction with health, the need for medical treatment, access to the information needed in everyday life, and the support respondents receive from their friends $(\mathrm{p}<0.05)$.

Many differences were observed in the case of satisfaction with health between NT and $\mathrm{P}(\mathrm{p}=0.00)$. The visually impaired athletes have estimated that they require a great deal of medical support in everyday life, but statistically significant differences were observed between them and NT ( $\mathrm{p}=0.03)$. The NT group were satisfied most with the ability of information needed in everyday life $(\mathrm{p}=0.03)$.

Table 2. The mean value of the quality of life based on the WHO-QOL-BREF questionnaire (only statistically significant differences were shown)

\begin{tabular}{|c|c|c|c|c|}
\hline \multirow{2}{*}{ Self-assessment of the quality of life } & \multicolumn{3}{|c|}{ Group } & \multirow[b]{2}{*}{$\mathbf{p}$} \\
\hline & $\mathbf{P}$ & $\mathbf{N}$ & NT & \\
\hline $\begin{array}{l}\text { How satisfied } \\
\text { are you with your health? }\end{array}$ & $4.2^{\mathrm{B}}$ & 3.9 & $3.1^{\mathrm{B}}$ & 0.01 \\
\hline $\begin{array}{l}\text { How much do you need medical } \\
\text { treatment to function in your daily life? }\end{array}$ & 4.4 & $4.7^{\mathrm{C}}$ & $3.6^{\mathrm{C}}$ & 0.03 \\
\hline $\begin{array}{l}\text { How available to you is the information } \\
\text { that you need in your day-to-day life? }\end{array}$ & 4.0 & $3.3^{\mathrm{C}}$ & $4.3^{\mathrm{C}}$ & 0.02 \\
\hline $\begin{array}{l}\text { How satisfied are you } \\
\text { with the support you get } \\
\text { from your friends? }\end{array}$ & $4.0^{\mathrm{B}}$ & 3.9 & $4.4^{\mathrm{B}}$ & 0.04 \\
\hline
\end{tabular}

Abbreviations as in Table 1

Source: own study.

The results regarding the difficulties people with visual impairment have in everyday life and thesupport they receive from others is shown in Table3. No statistically significant differences between groups were observed.

The results regarding the way in which participants moved in everyday life were received from the Retina AMD questionnaire. None of studied groups usea guide dog. In the untrained visually impaired (NT), $77 \%$ move alone, while $11 \%$ need a guide. The majority $(71 \%)$ of visually impaired athletes $(\mathrm{N})$ move without help, while $11 \%$ of them need a guide, and $5 \%$ a white cane.

Most respondents in both the sedentary group (84\%) and athletes (93\%) meet other visuallyimpaired people. Respondents from the sedentary group meet them more often (every day or almost every day - 38\%) than athletes (two or three times a month - 35\%). No contact with other blind people is due to the absence of knowing such people, or a lack of desire for such meetings. 
Table 3. Retina AMD questionnaire results

\begin{tabular}{llc}
\hline \multicolumn{1}{c}{ Question } & Group & NT \\
\hline \multicolumn{1}{c}{ The level of difficulty in everyday life: } & N & 1.1 \\
\hline Moving in their own home & 1.0 & 1.8 \\
Moving in the city & 1.6 & 1.3 \\
Getting to know when the day or night is & 1.5 & 1.6 \\
Understanding terms that are related to the sense of sight, for example, colors & 0.9 & 1.6 \\
Performing basic activities in daily life such as cooking & 1.6 & 2.1 \\
Ability to read others' emotions & 1.9 & 1.6 \\
Getting to know new people & 1.6 & 0.2 \\
Morning/evening toilet & 0.9 & 0.5 \\
Dressing up & 0.8 & 1.0 \\
Eating with a knife and fork & 0.9 & 1.4 \\
Travelling by bus, tram, train & 1.8 & 1.7 \\
Shopping & 1.6 & 1.2 \\
Walking in the street & 1.6 & 4.6 \\
\hline \multicolumn{1}{c}{ Support from: } & & 3.8 \\
\hline Family & 1.3 & 2.5 \\
Other people & 1.5 & 2.3 \\
Officials & 2.4 & 2.9 \\
Non-governmental organizations (NGOs) & 2.1 & 3.5 \\
Own doctor & 1.9 & 2.6
\end{tabular}

The difficulties in everyday life: 0 - no difficulty, 5 - very difficult. The support from different groups of people: 0 - lack of support, 5 - very much support

Abbreviations as in Table 1

Source: own study.

Table 4. Visual Eye Questionnaire results (1). First part: 1 - excellent; 5 - poor; second part: 1 - none; 5 - much

\begin{tabular}{ccc}
\hline Question & Group & NT \\
\hline $\begin{array}{c}\text { In general, would you say your overall health is } \\
\text { At the present time, would you say your eyesight using both eyes } \\
\text { (with glasses or contact lenses, if you wear them) is }\end{array}$ & 3.1 & 3.4 \\
\hline How much of the time do you worry about your eyesight? & 4.0 & 3.1 \\
\hline $\begin{array}{c}\text { How much difficulty do you have doing work or hobbies } \\
\text { that require you to see well close such as cooking, sewing, } \\
\text { fixing things around the house, or using hand tools? }\end{array}$ & $1.5^{*}$ & $2.2^{*}$ \\
\hline $\begin{array}{c}\text { Because of your eyesight, how much difficulty do you have } \\
\text { going down steps, stairs, and curbs in dim light or at night? }\end{array}$ & 3.5 & 2.9 \\
\hline $\begin{array}{l}\text { Because of your eyesight, how much difficulty do you have } \\
\text { visiting people in their homes, at parties, and in restaurants? }\end{array}$ & 2.6 & 2.6 \\
\hline $\begin{array}{c}\text { Because of your eyesight, how much difficulty do you have } \\
\text { going out to see movies, plays, and sports events? }\end{array}$ & 2.3 & 2.1 \\
\hline
\end{tabular}

Abbreviations as in Table 1; $* \mathrm{p}=0.04$

Table 5. Visual Eye Questionnaire results (2). 1 - all of the time; 5 - none of the time

\begin{tabular}{ccc} 
Question & Group & NT \\
\cline { 2 - 3 } $\begin{array}{c}\text { Are you limited in how long you can work } \\
\text { or do other activities because of your vision? }\end{array}$ & 2.5 & 2.1 \\
How much does pain or discomfort in or around your eyes, \\
$\begin{array}{c}\text { for example, burning, itching, and aching, } \\
\text { keep you from doing what you would like to be doing? }\end{array}$ & 3.0 & 3.2 \\
\hline
\end{tabular}

Abbreviations as in Table 1

Source: own study. 
Most untrained (83\%) and athletes (79\%) do not take part inclasses to improve vision. Some respondents either did not know where they could undergo rehabilitation or have had eye-surgery, so they do not need them. Those who participated in such classes were very happy with the results they obtained.

Most of N (78\%) declared that the group of their friends has not changed. Seventy-two percent of the sedentary visually impaired and $93 \%$ of athletes use a computeralone. Lack of skills and training to use a computer and financial issues were the main reasons for the lack of using one.

The results of the National Eye Institute questionnaire are given in tables 4, 5, and 6. Significant differences were observed in the questions regarding time spent on thinking about their own eyesight (Table 4; $\mathrm{p}=0.039$ ) and the feeling of frustration in everyday life (Table 6; $\mathrm{p}=0.037$ ).

Table 6. Visual Eye Questionnaire results (3). 1 - definitely true; 5 - definitely false

\begin{tabular}{ccc}
\hline Question & Group & NT \\
\cline { 2 - 3 } I stay home most of the time because of my eyesight. & 3.7 & 2.8 \\
I feel frustrated a lot of the time because of my eyesight. & $3.8^{*}$ & $3.0^{*}$ \\
I have much less control over what I do, because of my eyesight. & 2.8 & 2.5 \\
I need a lot of help from others because of my eyesight. & 3.0 & 2.6 \\
I worry about doing things that will embarrass myself in front of others, \\
because of my eyesight.
\end{tabular}

Abbreviations as in Table $1 ; * \mathrm{p}=0.02$

Source: own study.

Ninety-four percent of NT do not drive a car, while $65 \%$ of them have never driven a car, and $35 \%$ have given it up (all due to a eyesight defect). Eighty-three percent of visually impaired athletes $(\mathrm{N})$ do not drive a car, and their resignation was due to both amblyopia and other reasons.

\section{The correlation between physical activity and quality of life}

Moderate correlations between variables according to PA and QOL in all participantswere observed ( $\mathrm{r}$ magnitude between 0.50 and 0.63 ). The meaningfulness of life and life satisfaction depended on moderate physical activity around the house $(\mathrm{r}=0.54)$. The difficulties during morning and evening toilet $(\mathrm{r}=0.63)$ and dressing up ( $\mathrm{r}=0.51)$ correlated with cycling as a form of travel. Traveling by bike was associated with the ability to work $(\mathrm{r}=-0.55)$. The correlation between the state of eyesight and time spent sitting during weekdays was observed $(\mathrm{r}=0.52)$. Vigorous PA as a part of work was associated with embarrassment when doing things $(\mathrm{r}=0.56)$.

\section{Discussion}

Health-related quality of life is the main problem in the studies of many disciplines. The reason for this is the need to improve the physical and mental well-being of all people. Examples of patients requiring complex therapy are those with impaired eyesight. Visual impairment is not only a social problem for an individual, but also for the family, others, and the nation. Only properly conducted rehabilitation is able to give a chance to these people to function normally and return to their physical,social, and professional activity. In this case, motivating them to participate in recreation and sport is crucial.

The aim of our studies was to show positive relationship between regular physical activity (in this case cycling) and quality of life in visually impaired people. Even if the visual impairment is at the same level during all life, QOL could be much different. The main goal in these people everyday life should be to 
experience the possibilities of rehabilitation through recreation and sport. Thus, research showing positive influence of different activities on QOL as well as physiological variables should be undertaken. The evidence based medicine is the most important thing in the evaluation of rehabilitation process. Good diagnostic tool (e.g., validated questionnaires) in the assessment of physical activity and quality of life should be introduced. In our study International Physical Activity Questionnaire was also introduced. In the case of QOL questionnaires we used the most commonly used in Poland.

There is some research showing the positive influence of physical activity on quality of life. The group of blind people participating in torball at the age of 36 years demonstrated higher levels of socialization and better psychological well-being in relation to the untrained blind people (Di Cagno, Iuliano, Aquino et al., 2013). The positive impact of this sport can also be observed in self-reliance (Karakaya, Aki, \& Ergun, 2009) and motor skills development (Silva, Pereira, Depre, \& Gorla, 2010).

Success in blind and visually impaired tandem cycling depends on both partners and their ability to work together. Therefore, the question of athletic identity (AI) in sport has become a subject of research. Visually impaired athletes had lower rates of AI than their non-disabled partners. This could be related with greater responsibility and the need to assess the situation and decisions taken during a race with properly sighted cyclists. Greater responsibility allows them to have better AI. In addition, the objectives of sport are different for the visually impaired and properly sighted. People with disabilities want to meet new people, overcome weaknesses, and explore the world through sport (Tasiemski, Wilski, \& Mędak, 2012). In studies by Groff and Zabriskie, alpine skiing Paralympic athletes showed identical AI as able-bodied athletes in the same sports class (Groff, \& Zabriskie, 2006).

In our study, active visually impaired participants actively participated in studying and had higher education in comparison with sedentary lifestyle visually impaired participants. Moreover, $94 \%$ of $\mathrm{N}$ work, despite many impairments that occurred at birth.

In our study, physical activity was significantly different between the compared groups.

In visually impaired athletes, significantly greater physical activity with moderate intensity, moving by bike, and energy expenditure for vigorous recreational exercise and sport in leisuretime was observed. In contrast, sedentary lifestyle visually impaired people do not participate in sport compared to visually impaired athletes. Despite this, sedentary lifestyle people participated in moderate physical activity and took activities around the house. The highest value of time spent on vigorous physical activity in the garden or yard was recorded in NT. As a result, the total weekly energy expenditure on physical activity associated with the activities of life, recreation, and sport was not significantly different between people participating in cycling and sedentary lifestyle people.

In the case of recreation and sport, differences within vigorous physical activity were demonstrated. The most active groups were properly sighted and visually impaired athletes. According to other authors, physical and mental healthas well as quality of life assessment was higher in the group actively participating in sport (Dehkordi, 2011). In athletes, a significant increase in the level of happiness and development in mental strength were shown. The higher need to seek new experiences and satisfaction were also observed (Hajloo, \& Pezeshki, 2013). Moreover, athletes had a better incentive toward action and a better ability to cope in difficult situations (Mouratidis, \& Michou, 2011).The results ofour study showed that despite a significant level of amblyopia and many difficulties in everyday life, the respondents exhibit high motivation and have a satisfactory quality of life. In addition, respondents adapt well to situations that may hinder their functioning in the environment. The level of satisfaction with their health status was higher in the group of visually impaired athletes in comparison with sedentary people. Athletes spend less time thinking about the state of their eyesight compared to the inactive visually impaired. Tandem cyclists (N) also had greater opportunities to pursue their own interests than the sedentary visually impaired groups. The participation in physical activity can have a favorable impact on the subjective assessment of health and becomes the motivation to undertake recreational activities outside the home (see tables 4-6). All of the studied groups rarely experienced negative feelings such as sadness, depression, and despair. The highest rate 
to have the above-mentioned emotional disorders were observed in the inactive visually impaired. In addition, assessment of support they receive from others was the lowest in the $\mathrm{N}$ group. This could be due to the increased needs and requirements of those people.

As has been previously shown, participating in structured exercise programs (cycling training) has a beneficial effect on global (e.g., satisfaction with life, general psychological well-being) and specific (e.g., depression, anxiety) indices of mental health in active groups. An investigation into the relationship between PA and QOL was carried out in our studies. Moderate correlations between variables according to PA and QOL in all participants were observed. Life satisfaction was associated with the ability to participate in activities around the house, which means that more PA is related to higher satisfaction with life. The correlation between the state of eyesight and the time spent sitting during weekdays was also observed.Thus, it should be recommended to encourage inactive visually impaired people to participate in activities outside the home. This could prove better to those individuals that might dislike exercise, have little exercise experience or the ability to participate in sport, or are otherwise anxious about or averse to exercise participation with other people.

The practical implications of our work could be associated with the assessment and comparison of the quality of life in visually impaired and properly sighted, which could be the basis to find the effectiveness of rehabilitation programs in future. Such programs (based not only on cycling training) could be adapted and implemented in visually impaired people daily life. Physical activity program for people in working age or for children could be introduced and assessed in the case of its influence on QOL. But still more evidence is needed to determine more positive results of these programs on quality of life as well as physiological variables of people with disabilities.

\section{Conclusion}

Moderate correlations between variables according to physical activity and quality of life in all participants were found.The meaningfulness of life and life satisfaction was associated with moderate physical activity around the house, which could be the basis to encourage inactive visually impaired people to participate in activities outside the home. The obtained data indicate that all available forms of regular physical activity in visually impaired people could have a beneficial effect on their quality of life. Limitation of obtained results may be connected with used questionnaire methods and farther studies are need for confirmation of our data.

\section{Acknowledgment}

The study was conducted within the project DM 17 from Jozef Pilsudski University of Physical Education in Warsaw. Project leader: dr hab med. prof. AWF Krzysztof Mazurek.

\section{REFERENCES}

Auxter, D., Pyfer, J., \& Huettig, C. (1997). Principles and Methods of Adapted Physical Education and Recreation. St. Louis, MO: Mosby - Year Book, Inc.

Blachura, B., Blacha, R., \& Stefanowska, M. (2010). Psychosocial aspects of downhill skiing in visually impaired people. Science Dissertations of the University of Physical Education in Wroclaw, 31, 395-406.

Booth, M.L. (2000). Assessment of physical activity: An international perspective. Research Quarterly for Exercise \& Sport, 71(2), 114-120.

Chen, C-C, \& Lin, S-Y (2010). The impact of rope jumping exercise on physical fitness of visually impaired students. Research In Developmental Disabilities, 32 (1), 25-29.

Daszykowska, J. (2006). Quality of life in the health-related concepts. The University of Rzeszow Medical Review, 2, 122-128 /in Polish/. 
De Vries, J., \& Van Heck, G.L. (1997). The World Health Organization Quality of Life Assessment Instrument (WHOQOL-100): Validation study with the Dutch version. European Journal of Psychological Assessment, 13, 164161.

Dehkordi, A.G. (2011). The comparison between athlete females and non-athlete females regarding to general health, mental health, and quality of life. Procedia - Social and Behavioral Sciences, 15, 1737-1741.

Di Cagno, A., Iuliano, E., Aquino, G., et al. (2013). Psychological well-being and social participation assessment in visually impaired subjects playing Torball: A controlled study. Research In Developmental Disabilities, 34(4), 12041209.

Gąciarz, B., Ostrowska, A., \& Pańków, W. (2008). Social Integration and Occupation Activation of Disabled People Living in Small Towns and Rural Areas, Determinants of Success and Failure. IFiS PAN /in Polish/.

Groff, D. G., \& Zabriskie, R. B. (2006). An exploratory study of athletic identity among elite Alpine skiers with physical disabilities: Issues of measurement and design. Journal of Sport Behavior, 29, 126-141.

Hagströmer, M., Oja, P., \& Sjöström, M. (2006). The International Physical Activity Questionnaire (IPAQ): a study of concurrent and construct validity. Public Health Nutrition, 9(6), 755-762.

Hajloo, N., \& Pezeshki, H. (2013). Compare happiness, psychological tenacity, and sensation seeking among athletes and no athletes. Procedia - Social and Behavioral Sciences, 84(9), 1063-1066.

National Eye Institute. (1996, July). National Eye Institute Visual Functioning Questionnaire - 25 (VFQ-25). Retrieved May, 2013, from: http://www.nei.nih.gov/resources/visionfunction/vfq_ia.pdfRetina AMD Poland. Retrieved May, 2013, from: http://www.retinaamd.org.pl/

Karakaya, I.C., Aki, E., \& Ergun, N. (2009). Physical fitness of visually impaired adolescent goalball players. Percept Motor Skills, 108, 129-136.

Karwat, D., Jabłoński, L., \& Krupa, S. (2000). The dependence of the life comfort level in people with disabilities on family and social environment. In D. Karwat (Ed.), Adults' Disability and Rehabilitation as a Medical and Social Problem in Poland (pp. 182-186). Lublin, AM.

Kuru, E., \& Karahan, B.G. 2008. Physiological requirements of wheelchair and running basketball players. Selçuk University Journal for Physical Education and Sports Sciences, 10 (2), 23-30.

Langelaan, M., de Boer, M.R., van Nispen, R.M.A., et. al. (2007). Impact of visual impairment on quality of life: a comparison with quality of life in the general population and with other chronic conditions. In M. Langelaan (Ed.), Quality of Life of Visually Impaired Working Age Adults (pp. 105-124). The Netherlands: Print Partners.

Langelaan, M., van Nispen, R.M.A., Knol, D.L., et.al. (2007). Visual Functioning Questionnaire: Re-evaluation of psychometric properties for a group of working age adults. In M. Langelaan (Ed.), Quality of Life of Visually Impaired Working Age Adults (pp. 125-149). The Netherlands: Print Partners.

Midha, M., Schmitt, J.K., \& Sclater, M. (1999). Exercise effect with the wheelchair aerobic fitness trainer on conditioning and metabolic function in disabled persons: A pilot study. Archives of Physical Medicine and Rehabilitation, 80(3), 258-261.

Mikkelsen, S.S., Tolstrup, J.S., Flachs, E., et al. (2010). A cohort study of leisure time physical activity and depression. Preventive Medicine, 51, 471-475.

Morelli, T., Folmer, E., Foley, J.T., et al. (2011). Improving the Lives of Youth with Visual Impairments through Exergames. Fall, 4(4), 160-170.

Mouratidis, A., \& Michou, A. (2011). Perfectionism, self-determined motivation, and coping among adolescent athletes. Psychology of Sport and Exercise, 12(4), 355-367.

Movahedi, A., Mojtahedi, H., \& Farazyani, F. (2011). Differences in socialization between visually impaired studentathletes and non-athletes. Research In Developmental Disabilities, 32(1), 58-62.

Özer, D. (2001). Physical Education and Sports For Disabled People (pp. 4-21). Ankara: Nobel Publication Distribution.

Silva, G.P., Pereira, V.R., Deprá, P.P. et al. (2010). Tempo de reação e a eficiência do jogador de goalballnainterceptação/defesa do lançamento/ataque /Reaction time and efficiency of the goalball player in interception/defense of throwing/attack/. Motricidade, 6 (4), 13-22. 
Ströhle, A. (2009). Physical activity, exercise, depression and anxiety disorders.Journal of Neural Transmission, 116, 777-784.

Tasiemski, T., Wilski, M., \& Mędak, K. (2012). An assessment of athletic identity in blind and able-bodied tandem cyclists. Human Movement, 13(2), 178-184.

Teychenne, M., Ball, K., \& Salmon, J. (2008). Physical activity and likelihood of depression in adults: A review. Preventive Medicine, 46, 397-411.

Wolffsohn, J., Cochrane, A., \&Watt, N. (2000). Implementation methods for vision related quality of life questionnaires. British Journal Ophthalmology, 84(9), 1035-1040.

AUTHOR'S ADDRESS: $\quad$ Krzysztof Mazurek

Department of Sports Medicine

Jozef Pilsudski University of Physical Education in Warsaw

Marymoncka 34, 00-968 Warsaw, Poland

Faculty of Physical Education and Sport

Akademicka 2

21-500 Biała Podlaska, Poland

Email: kmazurek46@wp.pl

Received: 23 October 2014; Accepted: 20 December 2014 